\title{
Specific modulation of calmodulin activity induces a dramatic production of superoxide by alveolar macrophages
}

Robert Ten Broeke ${ }^{1}$, Thea Leusink-Muis ${ }^{1}$, Rogier Hilberdink ${ }^{1}$, Ingrid Van Ark ${ }^{1}$, Edwin van den Worm ${ }^{1}$, Matteo Villain ${ }^{2,3}$, Fred De Clerck ${ }^{1,4}$, J Edwin Blalock ${ }^{2}$, Frans P Nijkamp ${ }^{1}$ and Gert Folkerts ${ }^{1}$

${ }^{1}$ Department of Pharmacology and Pathophysiology, Utrecht Institute for Pharmaceutical Sciences, Utrecht University, Utrecht, The Netherlands; ${ }^{2}$ Department of Physiology and Biophysics, Center for

Neuroimmunology, University of Alabama at Birmingham, Birmingham, AL, USA; ${ }^{3}$ Department of Medicinal Biochemistry, University of Geneva, Geneva, Switzerland; ${ }^{4}$ Janssen Research Foundation, Beerse, Belgium

\begin{abstract}
Airway inflammation is a characteristic feature in airway diseases such as asthma and chronic obstructive pulmonary disease. Oxidative stress, caused by the excessive production of reactive oxygen species by inflammatory cells like macrophages, eosinophils and neutrophils, is thought to be important in the complex pathogenesis of such airway diseases. The calcium-sensing regulatory protein calmodulin (CaM) binds and regulates different target enzymes and proteins, including calcium channels. In the present study, we investigated whether $\mathrm{CaM}$, via the modulation of calcium channel function, influences $\left[\mathrm{Ca}^{2+}\right]_{i}$ in pulmonary inflammatory cells, and consequently, modulates the production of reactive oxygen species by these cells. This was tested with a peptide termed calcium-like peptide 2 (CALP2), which was previously shown to regulate such channels. Specifically, radical production by purified broncho-alveolar lavage cells from guinea-pigs in response to CALP2 was measured. CALP2 was a strong activator of alveolar macrophages. In contrast, CALP2 was only a mild activator of neutrophils and did not induce radical production by eosinophils. The CALP2induced radical production was mainly intracellular, and was completely blocked by the NADPH-oxidase inhibitor DPI, the superoxide inhibitor SOD and the CaM antagonist W7. Furthermore, the calcium channel blocker lanthanum partly inhibited the cellular activation by CALP2. We conclude that alveolar macrophages, but not neutrophils or eosinophils, can produce extremely high amounts of reactive oxygen species when stimulated via the calcium/CaM pathway. These results may contribute to new therapeutic strategies against oxidative stress in airway diseases.
\end{abstract}

Laboratory Investigation (2004) 84, 29-40, advance online publication, 20 November 2003; doi:10.1038/labinvest.3700002

Keywords: calcium-like peptide; calmodulin; chemiluminescence; macrophages; superoxide

Airway diseases such as asthma and chronic obstructive pulmonary disease (COPD) are characterized by airway hyper-responsiveness, epithelial damage, oxidative stress and airway inflammation. Inflammatory cells like macrophages, neutrophils, eosinophils and lymphocytes are crucial in the pathogenesis of asthma and COPD. ${ }^{1,2}$ In asthma, the increase in the number of eosinophils correlates in time with the development of bronchial hyperresponsiveness. ${ }^{3}$ In COPD, however, the neutrophil

Correspondence: Dr G Folkerts, Department of Pharmacology and Pathophysiology, Utrecht Institute for Pharmaceutical Sciences, PO Box 80.082, 3508 TB Utrecht, The Netherlands.

E-mail: G.Folkerts@pharm.uu.nl

Received 02 July 2003; revised 06 September 2003; accepted 14 September 2003; published online 20 November 2003 appears to be a critical cell, since there are increased numbers of neutrophils in the airways of COPD patients. ${ }^{4}$ Moreover, there is evidence that alveolar macrophages also contribute to the development of asthma and COPD. ${ }^{5,6}$ Indeed, macrophages release neutrophil chemotactic factors, which may be the driving force for the inflammatory process in COPD. ${ }^{6}$ Furthermore, macrophages produce oxygen radicals, such as superoxide anion $\left(\mathrm{O}_{2}^{-} \bullet\right)$, hydrogen peroxide $\left(\mathrm{H}_{2} \mathrm{O}_{2}\right)$, the hydroxyl radical $\left(\mathrm{OH}^{\bullet}\right)$ and nitric oxide (NO), which contributes to the pathogenesis of allergic reactions, epithelial cell damage as seen in asthma as well as an oxidant/antioxidant imbalance in COPD. ${ }^{6}$ The most predominant radical $\mathrm{O}_{2}^{-} \bullet$ is released during the respiratory burst of granulocytes and macrophages by NADPH-oxidase activity, in response to several stimuli. ${ }^{7,8}$ Superoxide 
rapidly reacts with $\mathrm{NO}$, yielding the highly reactive oxygen radical peroxynitrite $\left(\mathrm{ONOO}^{-}\right)$, which causes tissue injury and induces airway hyperresponsiveness. $^{9,10}$ Interestingly, Calhoun et $a l^{11}$ have shown that inflammatory cells isolated from the airways of asthmatic patients after allergen challenge release more superoxide than those from control subjects.

Calmodulin (CaM), the ubiquitous calcium-sensing regulatory protein, binds and regulates different target proteins, including protein kinases, ion channels and NO synthases. ${ }^{12}$ CaM has a structural motif, the EF hand, which binds calcium selectively and with high affinity. ${ }^{13}$ The signaling pathways leading to radical production in inflammatory cells include mainly the calcium-dependent phospholipase C-mediated phosphokinase $\mathrm{C}$ sequence, although also a variety of protein kinases are also known that are not dependent on the calcium signal. ${ }^{14}$ We recently described a 12 -mer peptide CALP2 with all characteristics necessary to define the role of CaM in the production of radicals by inflammatory cells. ${ }^{15,16}$ The peptide binds EF hand motifs of the calcium-binding proteins CaM and troponin C. Moreover, we showed that CALP2 inhibited the action of $\mathrm{CaM},{ }^{15,17}$ but increased $\left[\mathrm{Ca}^{2+}\right]_{i}$ in airway epithelial cells, the latter being accompanied by an increased NO production by these cells. ${ }^{18}$ Moreover, the effects of CALP2 were likely due to the sustained opening of calcium channels present in epithelial cells. ${ }^{18,19}$

In the present study, we used CALP2 to investigate the importance of $\mathrm{CaM}$ in radical production. For this purpose, radical production by bronchoalveolar lavage (BAL) cells from guinea-pigs was measured using lucigenin-enhanced chemiluminescence. $^{20}$ We found that CALP2 strongly activates alveolar macrophages for radical production. This effect was (1) accompanied by an increase in $\left[\mathrm{Ca}^{2+}\right]_{\mathrm{i}}$ in these cells and (2) blocked by the CaM antagonist W7. We conclude that alveolar macrophages can produce extremely high amounts of reactive oxygen species when stimulated via the calcium/CaM pathway.

\section{Materials and methods}

\section{Design of the Hydropathically Complementary Peptide CALP2}

The design of the complementary peptide CALP2 (VKFGVGFKVMVF) was carried out using the computer program AMINOMAT ${ }^{\mathbb{R}}$ (Tecnogen ScpA, Verna, Italy), with an averaging window $r=9$, a range of inverted hydropathy of 0.8 and also considering eight amino acids of the flanking regions. The program generated 1417176 possible sequences, and chose the one with the lowest $Q$ value (0.0068). The complementary peptide CALP1 (VAITVLVK) was used as a negative control peptide.

\section{Peptide Synthesis}

The peptides were synthesized by using continuous flow solid-phase peptide synthesis with Fmoc ( $N$-(9-fluorenyl)methoxycarbonyl) chemistry, on a PerSeptive Biosystems 9050 Peptide synthesizer. Preactivated $O$-pentafluorophenyl ester amino acids with 1-hydroxy-7-azabenzotriazole and preloaded polyethylene glycol graft polystyrene resin were used. The peptides were purified by preparative RP-HPLC. The purity of the products was checked by analytical RP-HPLC. The identity of the peptides was confirmed by TOF-MALDI MS (UAB Core Facility). CALP1 and CALP2 were stored at $4^{\circ} \mathrm{C}$ and dissolved in MilliQ water before each experiment.

\section{Lung Lavages}

Broncho-alveolar lavage (BAL) fluids were obtained from male Dunkin Hartley guinea-pigs (Harlan Olac Ltd, Blackthorn, England). Macrophages were derived from BAL fluid from naïve guinea-pigs and para-influenza-3 (PI-3) virus-infected guinea-pigs. For the latter, guinea-pigs were intratracheally inoculated with PI-3 virus (culture infective $\operatorname{dose}_{50}=10^{7.8} / \mathrm{ml}$ ) and four days later BAL cells were obtained..$^{18}$ Alveolar neutrophils were obtained from guinea-pigs treated with aerosolized LPS (endotoxin, Escherichia coli, $75 \mu \mathrm{g} / \mathrm{ml}$, Sigma, St Louis, MO, USA) for $30 \mathrm{~min}$. The cells were obtained $24 \mathrm{~h}$ after LPS treatment. For eosinophils, guinea-pigs were sensitized by subcutaneous injections with an allergen solution containing $20 \mu \mathrm{g}$ ovalbumin and $100 \mathrm{mg} \mathrm{Al}(\mathrm{OH})_{3}$ per $\mathrm{ml}$ saline. At 2 weeks after sensitization, the animals were challenged by exposure to aerosolized ovalbumin $(0.1 \% \mathrm{wt} / \mathrm{vol}$ in sterile saline). Eosinophils were obtained from the BAL fluid at $24 \mathrm{~h}$ after challenge.

For the isolation of BAL cells, the guinea-pigs received a lethal dose of pentobarbitone sodium (Euthesate ${ }^{\circledR} 0.6 \mathrm{~g} / \mathrm{kg}$ body weight, intraperitoneally). The trachea was trimmed free of connective tissue, and a small incision was made for insertion of a cannula into the trachea. The lungs were filled with $10 \mathrm{ml}$ sterile saline of $32^{\circ} \mathrm{C}$ in situ. After gentle lung massage for $1 \mathrm{~min}$, fluid was withdrawn from the lungs and collected in a plastic tube on ice. This procedure was repeated 3 times (total $40 \mathrm{ml}$ ) and the cell suspensions recovered from one animal were pooled. The cells was sedimented by centrifugation at $400 \mathrm{~g}$ for $10 \mathrm{~min}$ at $4^{\circ} \mathrm{C}$ and were washed twice with Krebs-bicarbonate buffer. A sample of the cells was stained with Türk's solution and counted in a Bürker-Türk bright-line counting chamber. All cell preparations were analyzed morphologically after centrifugation ( $45 \mathrm{~g}$ for $5 \mathrm{~min}$ at room temperature) on microscope slides. Air-dried preparations were fixed and stained with Diff-Quik (Merz + Dade AG, Düdingen, Switzerland). The cells were differentiated into 
alveolar macrophages, eosinophils, lymphocytes and neutrophils by light microscopical observation under oil immersion.

\section{Generation of Chemiluminescence}

Radical production was measured by lucigeninenhanced chemiluminescence in a 96-well plate luminometer (Fluoroskan Ascent FL, Labsystems Oy, Helsinki, Finland). Previously, this method was shown to be specific for the detection of superoxide anion. ${ }^{20-22}$ In each experiment, cells from individual animals were used. Cells obtained from one animal were used only once for control and stimulatory radical production (eg control, CALP1, PMA and CALP2; $n=1$ ). Experiments were carried out using four to six different animals $(n=4-6)$. The concentration of BAL cells from each animal was adjusted to give $10 \times 10^{6}$ cells $/ \mathrm{ml}$. The BAL cells were resuspended in Hanks' balanced salt solution (HBSS, Gibco BRL, Breda, The Netherlands). For some experiments, cells were resuspended in calciumfree HBSS (Gibco BRL, Breda, The Netherlands).

To perform experiments on a single cell type (eg macrophages, eosinophils or neutrophils), BAL cells were separated using density-gradient centrifugation over isotonic Percoll (55\% v/v, Pharmacia, North Peapack, NJ, USA). After separation, BAL cell suspensions consisted of 98\% macrophages, 97\% neutrophils and 98\% eosinophils, respectively.

Lucigenin was used at a final concentration of $500 \mu \mathrm{M}$. Phorbol myristate acetate (PMA, Sigma) was used as a cellular stimulant at final concentrations of 1,10 or $100 \mathrm{nM}$ (as indicated in the figures) in the reaction mixture. The calcium ionophore ionomycine (Sigma) was used at a final concentration of $10 \mu \mathrm{M}$ and CALP2 was used in different concentrations as indicated in the figures (final concentrations $0.2-20 \mu \mathrm{M}$ ). The control peptide CALP1 was used in a final concentration of $10 \mu \mathrm{M}$. The superoxide dismutase inhibitor superoxide dismutase polyethylene glycol (PEG-SOD, Sigma) $\left(\mathrm{IC}_{50}=50 \mathrm{U} / \mathrm{ml}\right),{ }^{23}$ the NADPH-oxidase inhibitor diphenylene iodonium chloride (DPI, Sigma) $\left(\mathrm{IC}_{50}=1 \mu \mathrm{M}\right),{ }^{24,25}$ the CaM antagonist $\mathrm{N}$-(6-aminohexyl)-5-chloro-1-naphthalenesulfonamide (W7, Sigma) $\left(\mathrm{IC}_{50}=20 \mu \mathrm{M}\right),{ }^{26,27}$ the store-operated channel blocker lanthanum $\left(\mathrm{La}^{3+}\right)$ chloride (Sigma) $\left(\mathrm{IC}_{50}=10 \mu \mathrm{M}\right)^{28,29}$ and the IP3receptor antagonist 2-aminoethoxydiphenyl borate (2-APB, Calbiochem, Bad Soden, Schwalbach, Germany)( $\left(\mathrm{IC}_{50}=42 \mu \mathrm{M}\right)^{30}$ were used as inhibitors at final concentrations of $100 \mathrm{U} / \mathrm{ml}, 10,50,10$ and $75 \mu \mathrm{M}$, respectively.

The final volume in each well was $250 \mu \mathrm{l}$. The broncho-alveolar cells ( $100 \mu \mathrm{l})$ were stimulated with: (A) control solution (HBSS), (B) $25 \mu \mathrm{l}$ CALP1 (=control peptide), (C) $25 \mu \mathrm{l}$ ionomycin, (D) $25 \mu \mathrm{l}$ PMA or (E) $25 \mu \mathrm{l}$ CALP2. When inhibitors were used, cells were incubated with $25 \mu \mathrm{l}$ of this inhibitor $10 \mathrm{~min}$ before stimulators were added.
Chemiluminescence was measured every 2 min for $60 \mathrm{~min}$ at $37^{\circ} \mathrm{C}$. The integrated response was determined with a computer program supplied with the luminometer. Data are presented as the total chemiluminescence production during $60 \mathrm{~min}$ (area under the curve (relative light units (RLU)*60 min)).

Similar experiments were performed on human blood neutrophils $\left(10 \times 10^{6} \mathrm{cells} / \mathrm{ml}\right)$. Therefore, neutrophils were isolated from venous blood of healthy volunteers (Bloedbank Midden-Nederland, Utrecht, The Netherlands) as described previously by Verbrugh et al. ${ }^{31}$

After every experiment, the viability of the cells was assessed by the Trypan blue extrusion test. No effect of any of the chemicals on cell viability was observed (data not shown).

\section{Measurement of Superoxide Production by Alveolar Macrophages}

Superoxide production was determined by a kinetic assay of the superoxide dismutase-inhibitable reduction of ferricytochrome $c .^{32}$ Therefore, freshly isolated alveolar macrophages from guinea-pigs were resuspended in HBSS $\left(10 \times 10^{6} \mathrm{cells} / \mathrm{ml}\right)$. Ferricytochrome $c$ was used at a final concentration of $100 \mu \mathrm{M}$. PMA and CALP2 were used at final concentrations of 0.1 and $20 \mu \mathrm{M}$ in the reaction mixture, respectively. SOD was used as an inhibitor at a final concentration of $100 \mathrm{U} / \mathrm{ml}$. The final volume in each well was $250 \mu \mathrm{l}$. The bronchoalveolar cells $(100 \mu \mathrm{l})$ were stimulated with: (A) control solution (HBSS), (B) $25 \mu \mathrm{l}$ PMA or (C) $25 \mu \mathrm{l}$ CALP2. When SOD was used, cells were incubated with $25 \mu \mathrm{l}$ of SOD for $10 \mathrm{~min}$ before stimulators were added. The optical density was read at $550 \mathrm{~nm}$ at $37^{\circ} \mathrm{C}$ during $60 \mathrm{~min}$, using a Benchmark microplate reader (Bio-Rad Laboratories, Hercules, CA, USA). Data are presented as the maximum response obtained during $60 \mathrm{~min}$.

\section{Measurement of Calcium in Alveolar Macrophages}

Freshly isolated alveolar macrophages from guinea pigs were resuspended in HBSS added with $0.1 \mathrm{mM}$ HEPES (Gibco BRL), 0.1\% fetal calf serum (FCS) and $2.5 \mathrm{mM}$ probenicid (Sigma). The cells were loaded with $4 \mu \mathrm{M}$ fura 2 -AM at room temperature for $1 \mathrm{~h}$ in the dark. Thereafter, the cells were washed 3 times and resuspended at a final concentration of $10 \times 10^{6} \mathrm{cells} / \mathrm{ml}$ in HBSS. For some experiments, cells were washed and resuspended in calcium-free HBSS. Cells were allowed to de-esterify for $30 \mathrm{~min}$ before they were used. Cells were placed in a 96well plate at a concentration of $1 \times 10^{6}$ cells/well. The cells were stimulated with control solution, CALP1 $(10 \mu \mathrm{M})$, PMA $(0.1 \mu \mathrm{M})$ or CALP2 $(20 \mu \mathrm{M})$ and fluorescence of Fura 2, alternately excited at 340 and $380 \mathrm{~nm}$ with $5 \mathrm{~s}$ interval, was monitored at 510 nm using a Fluoroskan Ascent FL (Labsystems 
Oy, Helsinki, Finland). The ratio of the two images $\left(F_{340} / F_{380}\right)$ was determined. The maximum and minimum fluorescence intensities were obtained with $0.1 \%$ Triton X-100 and $10 \mathrm{mM}$ EGTA in $2 \mathrm{M}$ Tris-HCl, pH 8.5, respectively.

\section{Statistical Analysis}

Differences in chemiluminescence production due to agonist stimulation was tested using the Student's $t$-test (unpaired). When the effect of inhibitors was tested, data were statistically analyzed using ANOVA followed by post-hoc pair wise comparison of the effects of the inhibitor compared to control levels. All $P$-values $<0.05$ were considered to reflect a statistically significant difference.

\section{Results}

\section{Effect of Ionomycin, PMA and CALP2 on Chemiluminescence Production by Alveolar Macrophages}

Lucigenin-enhanced chemiluminescence production was used to investigate the effects of ionomycin, PMA and CALP2 on reactive oxygen species production by alveolar macrophages. Therefore, BAL cells from naive guinea-pigs were used, which consist of $88 \%$ macrophages (Figure 1). Typical tracings of chemiluminescence production by alveolar macrophages after stimulation with ionomycin, PMA or CALP2 are shown in Figure 2. Basal chemiluminescence production during $60 \mathrm{~min}$ by macrophages was $490 \pm 47$ RLU (Figure 3). The calcium ionophore ionomycin increased the basal response to $748 \pm 119$ RLU $(P<0.05)$. The chemiluminescence production was increased only briefly after application of the ionophore (Figure 2, inset); this explains the slight increase in production during $60 \mathrm{~min}$ (Figure 3). PMA dose-dependently increased radical production to $918 \pm 28$ RLU.

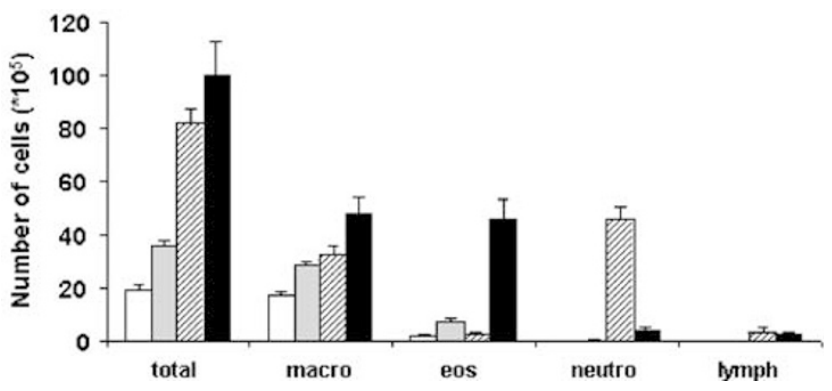

Figure 1 Total and differential number of BAL cells obtained from naive (white bars), PI-3 virus-treated (gray bars), endotoxintreated (hatched bars) and ovalbumin-sensitized/-challenged (black bars) guinea-pigs. Data are expressed as number of BAL cells (mean \pm s.e.m., $n=6$ ). PI-3 virus treatment results in an increase in macrophages and eosinophils. Endotoxin treatment results in an increase in neutrophils in BAL fluid, whereas ovalbumin challenge increases the number of eosinophils in BAL fluid.

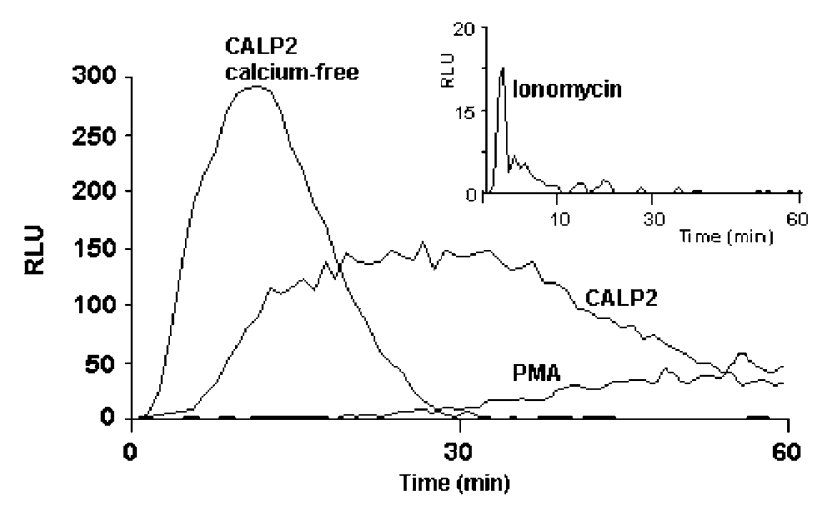

Figure 2 Typical tracing of chemiluminescence production during 60 min by macrophages upon stimulation with ionomycin (10 $\mu \mathrm{M}$, inset), PMA $(0.1 \mu \mathrm{M})$, CALP2 $(20 \mu \mathrm{M})$ and CALP2 $(20 \mu \mathrm{M})$ in calcium-free medium. Chemiluminescence production is expressed as RLU. Ionomycin and CALP2 increased radical production shortly after application, whereas PMA-stimulated production started $20 \mathrm{~min}$ after application.

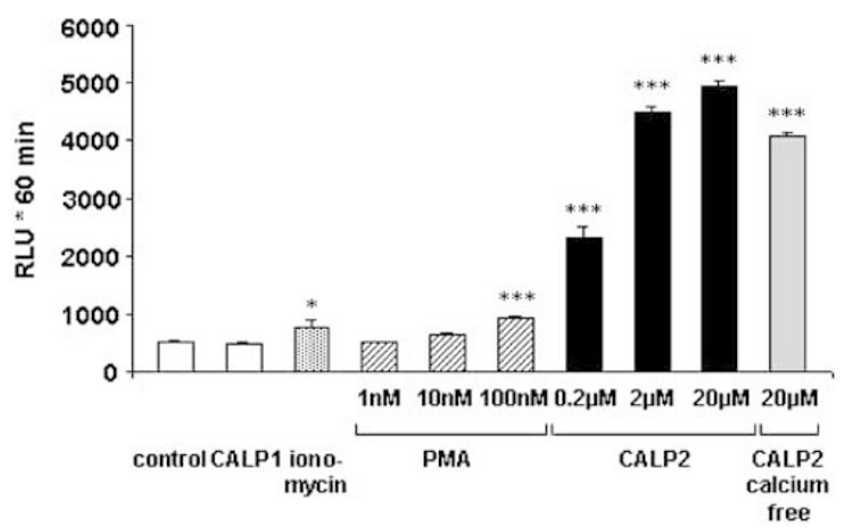

Figure 3 Chemiluminescence production by macrophages upon stimulation with control solution (white bar), the control peptide CALP1 $(10 \mu \mathrm{M}$, light-gray bar), ionomycin (10 $\mu \mathrm{M}$, dotted bar), increasing concentrations of PMA (hatched bars) and CALP2 (black bars) and CALP2 $(20 \mu \mathrm{M})$ in calcium-free medium (darkgray bar). Chemiluminescence production is expressed as the area under the curve $(R L U \times 60$ min, mean \pm s.e.m., $n=4)$. PMA and CALP2 dose-dependently increased radical production by macrophages. CALP2 also increased radical production in calcium-free medium. ${ }^{*} P<0.05,{ }^{* *} P<0.001$, Student's unpaired $t$-test compared to control.

CALP2 also dose-dependently increased the production of radicals $(P<0.001)$. However, CALP2 was a five times more effective inducer than PMA, since the RLU was increased to $4958 \pm 65$ at the highest CALP2 concentration (Figure 3). Also, CALP2 $(20 \mu \mathrm{M})$ stimulated radical production in calciumfree medium (4067 \pm 71 RLU). However, in this medium there was a different kinetic profile with an initial high increase in radical production, which stopped after $30 \mathrm{~min}$ of stimulation (Figure 2). The negative control peptide CALP1 had no effect on chemiluminescence (Figure 3 ). 
CALP2-induced Radical Production is Mainly Intracellular and is Blocked by PEG-SOD and DPI

To investigate which radical is mainly produced by alveolar macrophages after stimulation with CALP2, we performed experiments in the presence of the membrane-permeable PEG-SOD. It was found that the response to both PMA and CALP2 could be completely inhibited by PEG-SOD $(P<0.001$; Figure 4a). Moreover, the PMA- and CALP2-induced radical production could be completely blocked by the NADPH-oxidase inhibitor DPI (Figure 4b). We further investigated whether CALP2-induced superoxide production is intracellular or extracellular. For this purpose, we used the superoxide dismutase-inhibitable reduction of ferricytochrome $c$, which only detects extracellular superoxide production. ${ }^{32}$ The activation of alveolar macrophages with PMA resulted in extracellular radical production, which could be inhibited by SOD (Figure 5).
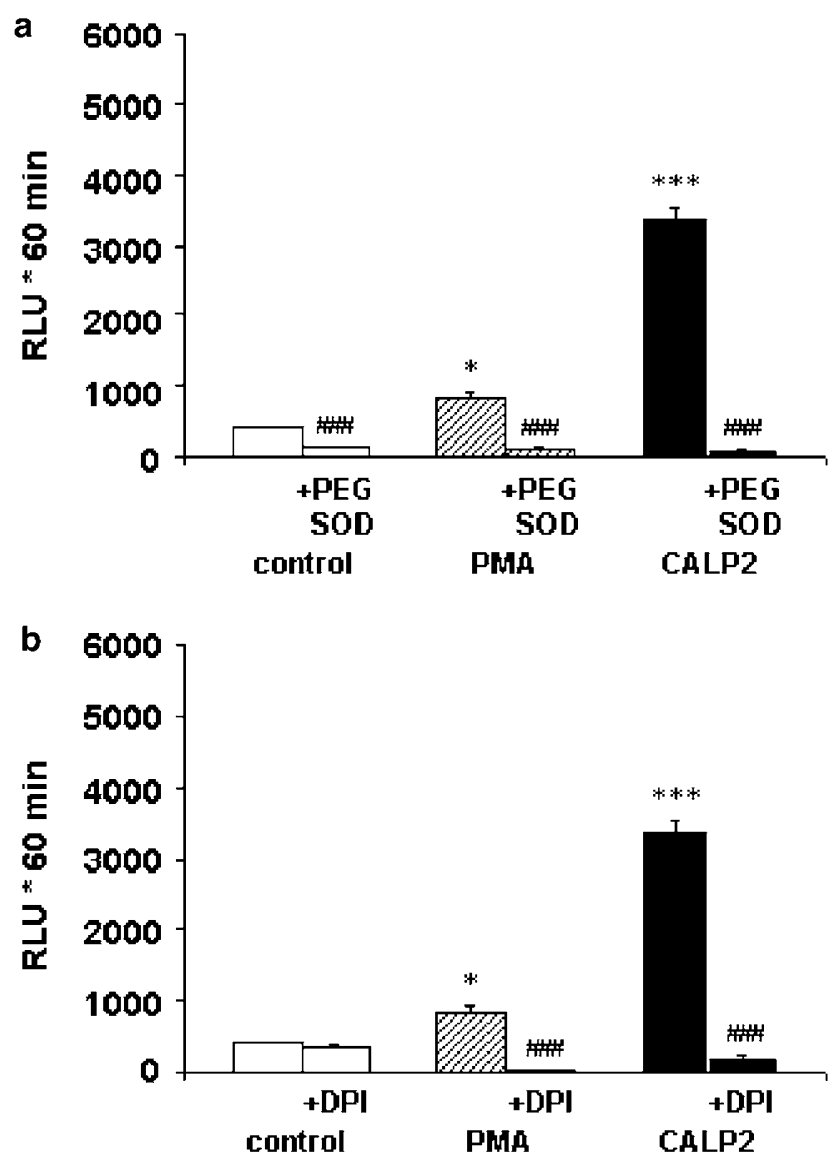

Figure 4 Inhibition of chemiluminescence production by (a) PEG-SOD (100 U/ml) and (b) DPI $(10 \mu \mathrm{M})$ of alveolar macrophages upon stimulation with control solution (white bars), PMA ( $0.1 \mu \mathrm{M}$; hatched bars) and CALP2 $(20 \mu \mathrm{M}$; black bars). Chemiluminescence production is expressed as RLU $\times 60$ min (mean \pm s.e.m., $n=4$ ). PEG-SOD and DPI completely inhibited the oxygen radical production by macrophages after stimulation with PMA and CALP2. ${ }^{*} P<0.01,{ }^{* *} P<0.001$, ANOVA compared to control. ${ }^{\# \# P} P<0.01,{ }^{\# \# \# P} P<0.001$, ANOVA compared to respective stimulus without an inhibitor.

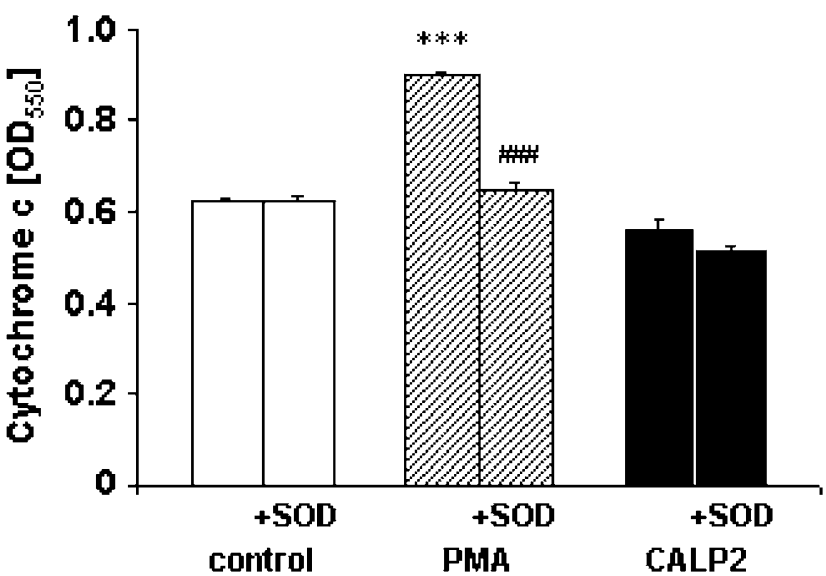

Figure 5 Ferricytochrome $c$ assay of alveolar macrophages after stimulation with control solution (white bars), PMA $(0.1 \mu \mathrm{M}$; hatched bars) and CALP2 $(20 \mu \mathrm{M}$; black bars). Only PMA stimulation resulted in extracellular superoxide production. Data are expressed as optical density at $550 \mathrm{~nm}\left(\mathrm{OD}_{550}\right)$. ${ }^{*} P<0.01,{ }^{* *} P<0.001$, ANOVA compared to control. ${ }^{\# \# \#} P<0.001$, ANOVA compared to respective stimulus without inhibitor.

Interestingly, CALP2-induced radical production was mainly intracellular, since no reduction of ferricytochrome $c$ could be observed after CALP2 stimulation (Figure 5).

These results show that CALP2 is a very potent activator of alveolar macrophages of guinea-pigs and that superoxide anion, released intracellularly by NADPH-oxidase, is the main oxygen radical produced by CALP2 stimulation.

\section{Effect of PMA and CALP2 on Chemiluminescence Production by Alveolar Neutrophils}

Next it was investigated as to whether CALP2 also stimulates alveolar neutrophils. Therefore, BAL cells from LPS-treated guinea-pigs were used, which consists of $40 \%$ macrophages and $56 \%$ neutrophils (Figure 1). Neutrophils were sepaqrated using a Percoll density gradient. Basal chemiluminescence production by neutrophils was $127 \pm 28$ RLU (Figure 6a). PMA increased the radical production to $2817 \pm 334$ RLU $(P<0.001)$. CALP2 only slightly increased the production of radicals by neutrophils to $827 \pm 156$ $(P<0.01$; Figure 6a). Again, the negative control peptide CALP1 had no effect on chemiluminescence production (Figure 6a). In the presence of the membrane-permeable PEG-SOD, the response of alveolar neutrophils to both PMA and CALP2 could be completely inhibited $(P<0.001$; Figure 6a). Similar results were found with unstimulated neutrophils isolated from human blood (Figure 7), indicating that primed neutrophils have effects similar to PMA and CALP2 compared to resident cells. 
34
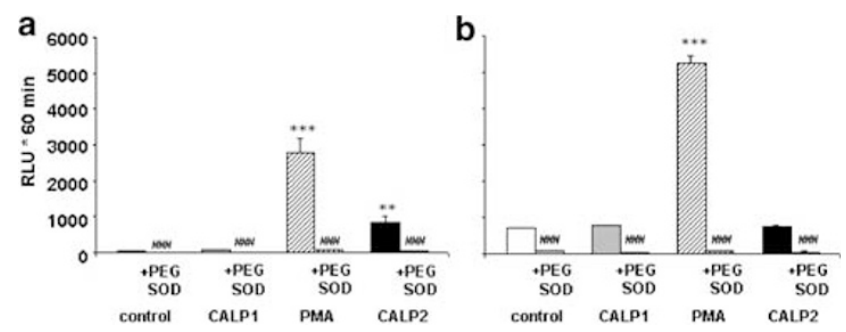

Figure 6 Chemiluminescence production by isolated alveolar (a) neutrophils and (b) eosinophils upon stimulation with control solution (white bar), the control peptide CALP1 (10 $\mu \mathrm{M}$, gray bar), PMA $(0.1 \mu \mathrm{M}$, hatched bar) and CALP2 (20 $\mu \mathrm{M}$, black bar). PEGSOD completely inhibited the oxygen radical production by both alveolar neutrophils (a) and eosinophils (b) after stimulation with PMA and CALP2. Chemiluminescence production is expressed as RLU $\times 60$ min (mean \pm s.e.m., $n=4$ ). PMA highly and CALP2 slightly increased radical production by neutrophils. Radical production by eosinophils was increased after stimulation with PMA, but CALP2 had no effect on this production. ${ }^{*} P<0.01$, ${ }^{* *} P<0.001$, ANOVA compared to control. ${ }^{\# \#} P<0.001$, ANOVA compared to respective stimulus without inhibitor.

\section{Effect of PMA and CALP2 on Chemiluminescence Production by Alveolar Eosinophils}

To investigate the effect of CALP2 on radical production by alveolar eosinophils, BAL cells from ovalbumin sensitized and challenged guinea-pigs were used. This cell population contains $48 \%$ macrophages and 46\% eosinophils (Figure 1). Eosinophils were separated using a Percoll density gradient. Basal chemiluminescence production by eosinophils was $707 \pm 7$ RLU (Figure 6b). PMA increased the radical production to $5265 \pm 187 \mathrm{RLU}$ $(P<0.001)$. CALP2 had no effect on the radical production by alveolar eosinophils $(733 \pm 50$ RLU; Figure 6b). The negative control peptide CALP1 had no effect on chemiluminescence production either (Figure 6b). In the presence of PEG-SOD, the response of alveolar eosinophils to PMA could be completely inhibited $(P<0.001$; Figure $6 b)$.

\section{Effect of CALP2 on Chemiluminescence Production by Primed Macrophages}

Since in the previous experiments preactivated neutrophils and eosinophils were used, we also primed alveolar macrophages to investigate whether CALP2 responses are different between naive macrophages and preactivated macrophages. For this purpose, we used alveolar macrophages obtained from PI-3 virus-infected guinea-pigs (Figure 1). These cells show greater responses to PMA (Figure 8), indicating an activated state of the macrophages. ${ }^{33}$ As shown in Figure 8, no difference in the CALP2 response was observed between naive macrophages and primed macrophages from PI-3 virus-infected guinea-pigs. Together with the results obtained from isolated unstimulated blood neutrophils (Figure 7), these findings again show that the priming of alveolar cells does not alter the response to CALP2.

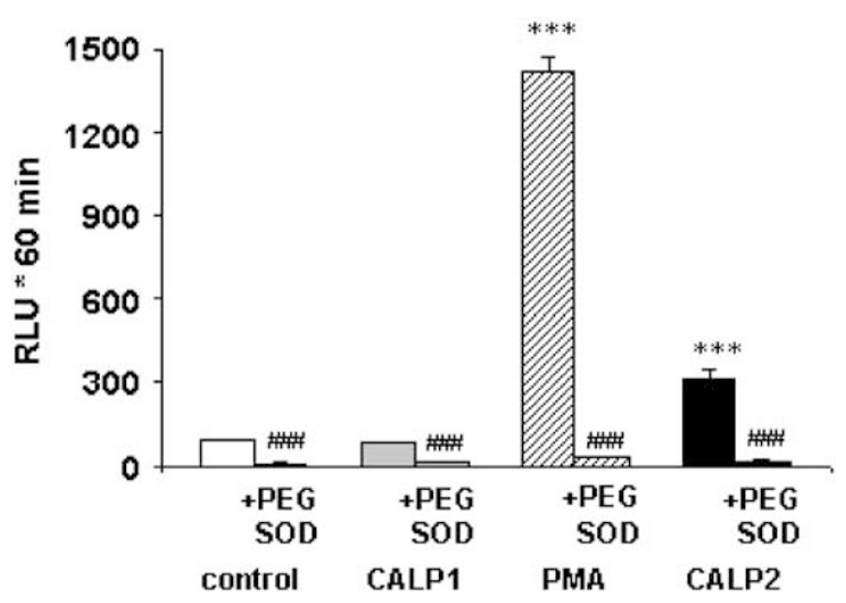

Figure 7 Chemiluminescence production by isolated human blood neutrophils. Cells were stimulated with control solution (white bar), the control peptide CALP1 $(10 \mu \mathrm{M}$, gray bar), PMA $(0.1 \mu \mathrm{M}$, hatched bar) and CALP2 $(20 \mu \mathrm{M}$, black bar). Chemiluminescence production is expressed as RLU $\times 60 \mathrm{~min}$ (mean \pm s.e.m., $n=6$ ). PEG-SOD completely inhibited the oxygen radical production by human blood neutrophils after stimulation with PMA and

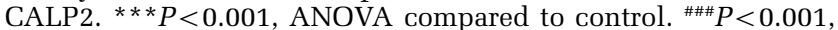
ANOVA compared to respective stimulus without inhibitor.

\section{CALP2 Increases $\left[\mathrm{Ca}^{2+}\right]_{i}$ in Alveolar Macrophages}

Previously, we showed that CALP2 blocks the action of the calcium-regulatory protein CaM. ${ }^{15}$ Interestingly, this resulted in an increase of $\left[\mathrm{Ca}^{2+}\right]_{\mathrm{i}}{ }^{18}$ Therefore, we hypothesized that the action of CALP2 on superoxide production by alveolar macrophages is due to the inhibition of $\mathrm{CaM}$ activation and therefore an increase of $\left[\mathrm{Ca}^{2+}\right]_{\mathrm{i}}$ in these cells. The basal fluorescence ratio $\left(F_{340} / F_{380}\right)$ in alveolar macrophages was $1.85 \pm 0.01$ (Figure 9). PMA stimulation only slightly increased $F_{340} / F_{380}$ $(2.45 \pm 0.01, P<0.001)$. CALP2, however, increased $F_{340} / F_{380}$ in macrophages to $4.21 \pm 0.05(P<0.001$; Figure 9). The negative control peptide CALP1 had no effect on $F_{340} / F_{380}$. In calcium-free medium, CALP2 slightly, but significantly, increased $F_{340} /$ $F_{380}(P<0.05$; Figure 9$)$. The increase in $\mathrm{F}_{340} / \mathrm{F}_{380}$ was $50 \%$ of the total release from intracellular stores as measured by the administration of the $\mathrm{Ca}^{2+}$-ATPase inhibitor thapsigargin (data not shown). From this, we conclude that CALP2 increases $\left[\mathrm{Ca}^{2+}\right]_{\mathrm{i}}$ in alveolar macrophages due to both release from intracellular stores and influx of extracellular calcium.

\section{Inhibition of the CALP2-induced Radical Production by W7, 2-APB and Lanthanum}

To investigate the hypothesis that radical production by CALP2 is due to modulation of activation of $\mathrm{CaM}$, chemiluminescence experiments were performed on alveolar macrophages in the presence of the CaM antagonist W7. Basal chemiluminescence production was $587 \pm 48$ RLU (Figure 10a), which was 


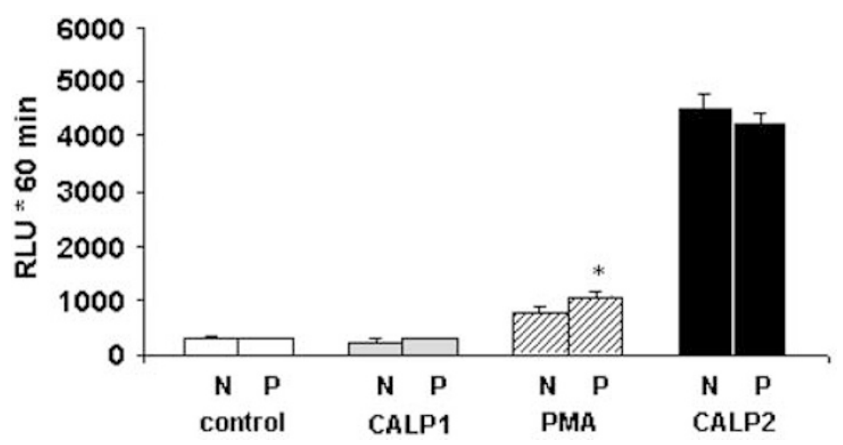

Figure 8 Chemiluminescence production by alveolar macrophages from naive control animals (N) and PI-3 virus-infected guinea-pigs (P). Cells were stimulated with control solution (white bars), the control peptide CALP1 (10 $\mu \mathrm{M}$, gray bars), PMA ( $0.1 \mu \mathrm{M}$, hatched bars) and CALP2 (20 $\mu \mathrm{M}$, black bars). Chemiluminescence production is expressed as $\mathrm{RLU} \times 60 \mathrm{~min}$ (mean \pm s.e.m., $n=6$ ). Radical production in PI-3 virus treated animals was slightly increased after stimulation with PMA. No difference in CALP2-induced radical production by macrophages was found between control animals and PI-3-infected animals. ${ }^{*} P<0.01$, Student's unpaired $t$-test compared to respective naïve control.

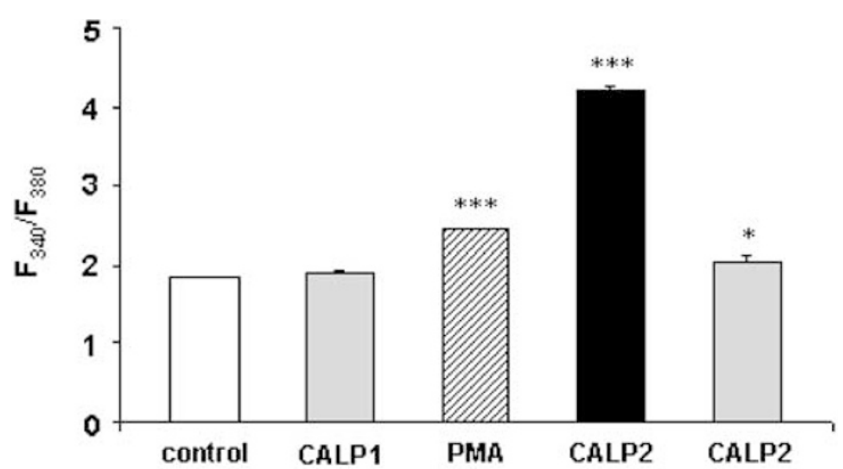

Figure 9 Increase in intracellular calcium concentrations $\left[\mathrm{Ca}^{2+}\right]_{\mathrm{i}}$ in alveolar macrophages measured with fura-2 imaging. Cells were stimulated with control solution (white bar), the control peptide CALP1 $(10 \mu \mathrm{M}$, light-gray bar), PMA $(0.1 \mu \mathrm{M}$; hatched bar), CALP2 (20 $\mu \mathrm{M}$; black bar) or CALP2 (20 $\mu \mathrm{M}$; dark-gray bar) in calcium-free medium. PMA slightly and CALP2 highly increased $\left[\mathrm{Ca}^{2+}\right]_{\mathrm{i}}$ in macrophages. CALP2 slightly increased $\left[\mathrm{Ca}^{2+}\right]_{\mathrm{i}}$ in calcium-free medium. Data are presented as mean \pm s.e.m., $n=4$ of similar experiments on one day. Similar results were seen on three consecutive days. ${ }^{*} P<0.05,{ }^{* * *} P<0.001$, Student's unpaired $t$-test compared to control.

partly inhibited by W7 $(110 \pm 11$ RLU, $P<0.001)$. Moreover, W7 completely inhibited CALP2-induced chemiluminescence production by macrophages $(4072 \pm 205 \mathrm{RLU}$ for CALP2 and $171 \pm 17 \mathrm{RLU}$ for W7 + CALP2, $P<0.001$; Figure 10a). To further explore the effects of CALP2, we performed experiments in the presence of the $\mathrm{IP}_{3}$-receptor antagonist 2 -APB and the calcium channel ( $\mathrm{I}_{\mathrm{CRAC}}$ ) blocker lanthanum. Both 2-APB $(26 \%, P<0.05)$ and lanthanum $(18 \%, P<0.001)$ partly inhibited the effects of CALP2 (Figure 10b and c, respectively). From this, we conclude that CaM is crucial for the production of reactive oxygen species by CALP2 in alveolar macrophages.
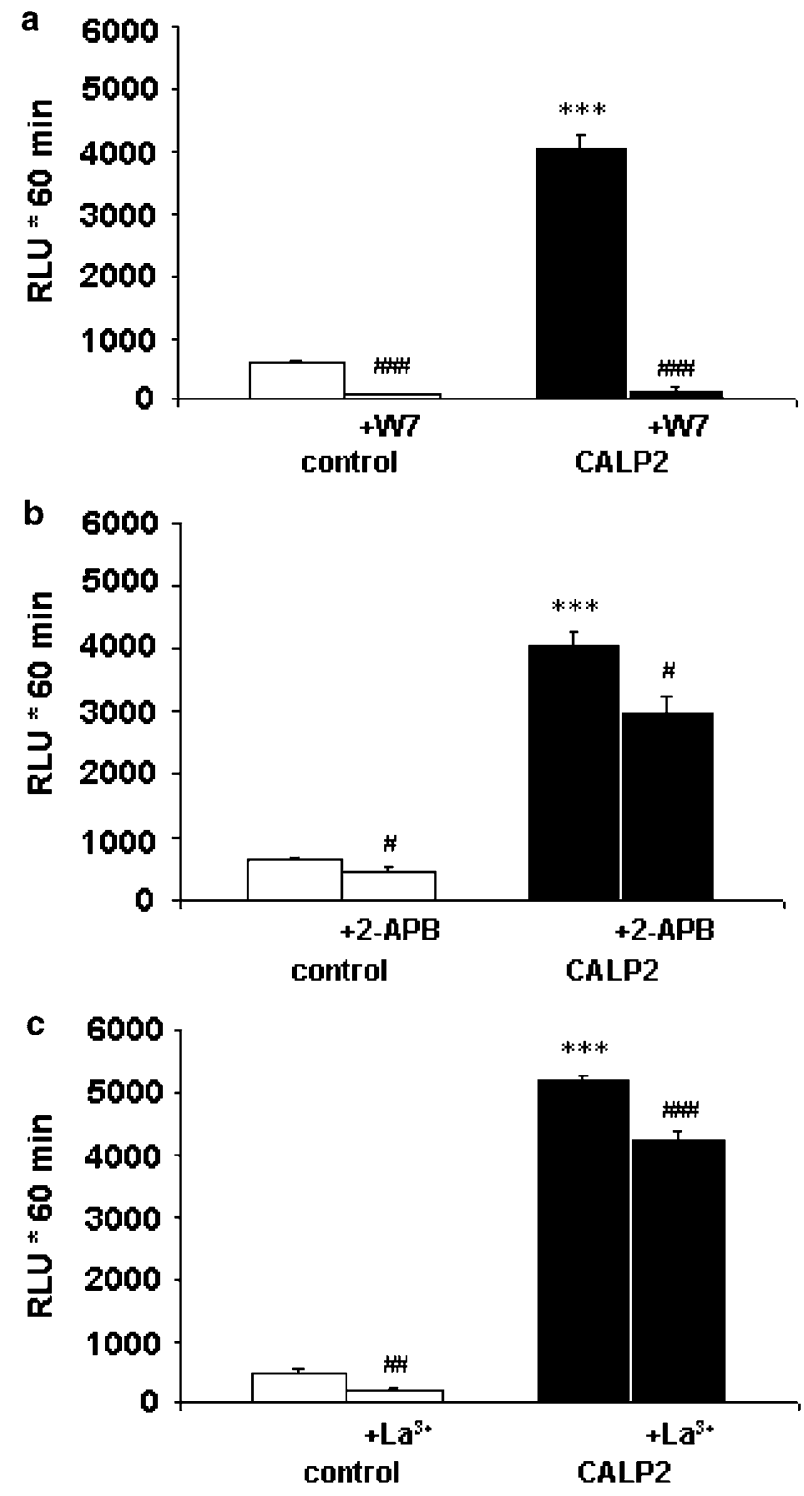

Figure 10 Inhibition of CALP2-induced radical production by alveolar macrophages. (a) Inhibition of control (white bars) and CALP2-induced ( $20 \mu \mathrm{M}$, black bars) radical production by W7. (b) Inhibition of control (white bars) and CALP2-induced $(20 \mu \mathrm{M}$, black bars) radical production by the $\mathrm{IP}_{3} \mathrm{R}_{1}$ antagonist 2-APB and (c) Inhibition of control (white bars) and CALP2-induced (20 $\mu \mathrm{M}$, black bars) radical production by the store-operated channel blocker lanthanum $\left(\mathrm{La}^{3+}\right)$. Chemiluminescence production is expressed as RLU $\times 60$ min (mean \pm s.e.m., $n=4$ ). W7 completely and 2-APB and lanthanum partly inhibited the oxygen radical production by macrophages. ${ }^{* * *} P<0.001$, ANOVA compared to control. ${ }^{\#} P<0.05$, ${ }^{\# \#} P<0.01,{ }^{\# \#} P<0.001$, ANOVA compared to respective stimulus without inhibitor.

\section{Discussion}

Research on the role of reactive oxygen species in several inflammatory diseases, especially asthma and COPD, may provide new insights into the pathogenesis of these diseases. Neutrophils and macrophages are likely to play key roles in the development of COPD, ${ }^{2}$ whereas eosinophils are the predominant cells involved in the pathogenesis of 
asthma. The exact role for the alveolar macrophage in asthma seems to be complex, since some researchers postulate the involvement of macrophages and their products, whereas others do not. ${ }^{1,5,11,34-36}$

The inflammatory cells generate reactive oxygen species that might be crucial in airway inflammation. Although their production is increased in asthma and COPD, ${ }^{11,37}$ the exact role of reactive oxygen species is not fully understood. The late airway response in asthma is characterized by the appearance of high-density alveolar macrophages with potentiated superoxide release.$^{11}$ Also, macrophages have a primary role in regulating the inflammatory response and tissue destruction in COPD. ${ }^{6}$ These macrophages release chemotactic factors, leading to increased neutrophils in the airways of COPD patients. ${ }^{4}$ Evidence from The European Network For Understanding Mechanisms of Severe Asthma (ENFUMOSA) project suggests that neutrophils contribute to airflow obstruction and epithelial damage in asthma. ${ }^{38}$

Reactive oxygen species induce oxidative stress and oxygen metabolites contribute to epithelial damage and consequently airway hyper-responsiveness, which are characteristic features of asthma. ${ }^{39,40}$ Furthermore, oxidative processes have a fundamental role in patients with COPD, since they increase $\mathrm{NF}-\kappa \mathrm{B}$ activation, which in turn leads to the release of inflammatory mediators such as interleukin-8, interleukin-1 and tumor necrosis factor $\alpha_{.}^{41}$ Moreover, increasing evidence suggests roles for oxygen radicals in intracellular signaling and as inducers of apoptosis. ${ }^{42,43}$ Inhibition of the respiratory burst by macrophages (and other inflammatory cells) may therefore be a useful target for new therapeutic targets for asthma and COPD. ${ }^{41,44}$ Furthermore, knowing the exact mechanisms by which inflammatory cells produce reactive oxygen species may be even more important.

In 1984, it was shown that radical production by macrophages is due to a rise in $\left[\mathrm{Ca}^{2+}\right]_{\mathrm{i}}{ }^{45}$ The source for the increase in $\left[\mathrm{Ca}^{2+}\right]_{\mathrm{i}}$ was mainly extracellular calcium. In the present study, we showed that the calcium-regulatory protein $\mathrm{CaM}$ is essential in radical production by alveolar macrophages. To address this issue, the selective $\mathrm{CaM}$ inhibitor CALP2 ${ }^{15}$ was used, and we found that CALP2 is a very potent activator of macrophages. Interestingly, we have shown that CALP2 only slightly activates neutrophils, whereas eosinophils were not activated at all. Although macrophages were obtained from naïve guinea-pigs and neutrophils and eosinophils were obtained after exposure of the airways to inflammatory stimuli, several data support our hypothesis that the altered responses to CALP2 are not due to different activation states of the cells. First, all used cell types still responded to PMA. Second, alveolar macrophages activated in vivo with PI-3 virus, ${ }^{33,46-48}$ showed the same response to CALP2 compared to naïve macrophages. Third, responses to CALP2 of isolated unstimulated blood neutrophils were comparable with responses of lung neutrophils obtained after LPS exposure.

We have shown that the CALP2-induced radical production was five times larger than that of the PKC stimulator PMA. Interestingly, CALP2-induced radical production was mainly intracellular, whereas PMA-induced radical production was, at least partly, extracellular. Since CALP2-induced chemiluminescence production was much higher (six times) than that of the phagocytotic compound zymosan, we can exclude the possibility that the radical production by CALP2 is due to phagocytosis by macrophages. Furthermore, CALP2 increased $\left[\mathrm{Ca}^{2+}\right]_{\mathrm{i}}$ in these cells. The cell-permeable PEGSOD, ${ }^{49}$ completely inhibited the response of CALP2. Therefore, intracellular superoxide seems to be the main radical produced by CALP2 stimulation.

The NADPH-oxidase system constitutes the primary defense mechanism against microbial infections. The superoxide release is mainly produced extracellularly; this may also cause severe tissue damage and induce inflammatory responses in asthma and COPD. Since the radical production by CALP2 was mainly intracellular, it is likely that the CALP2-induced superoxide production is involved in cellular signaling processes, but not tissue damaging. ${ }^{50}$ The role of reactive oxygen species in cell signaling includes a rapid increase in $\left[\mathrm{Ca}^{2+}\right]_{\mathrm{i}}$ in the cytoplasm of diverse cell types, ${ }^{51}$ which might lead to apoptosis. ${ }^{52}$ This increase is both due to calcium release from stores and extracellular calcium influx. Moreover, the increase in $\left[\mathrm{Ca}^{2+}\right]_{\mathrm{i}}$ subsequently leads to a further activation of several enzymes involved in radical production, including NOS and NADPH-oxidase, resulting in a sustained increase in radical production. We therefore postulate that CALP2, directly or indirectly, activates $\mathrm{CaM}$, which results in intracellular radical production, which subsequently increases $\left[\mathrm{Ca}^{2+}\right]_{\mathrm{i}}$, leading to a further increase in radical production. In addition, CALP2 might inhibit the negative feedback mechanism involved in calcium channel functioning described hereafter, and in this way modulate calcium-and radical responses in the cell.

Previously, we showed that CALP2 also increases $\left[\mathrm{Ca}^{2+}\right]_{\mathrm{i}}$ and nitric oxide production in airway epithelial cells. ${ }^{18}$ It was hypothesized that CALP2, as a CaM antagonist, opens calcium channels in airway epithelial cells, leading to calcium influx in these cells. ${ }^{18,53,54}$ Therefore, we now postulate that the production of radicals by CALP2 in macrophages is predominantly due to an increase of $\left[\mathrm{Ca}^{2+}\right]_{\mathrm{i}}$. Although less than in the presence of extracellular calcium, we found that macrophages still produce radicals upon stimulation with CALP2 in calcium-free medium. This production was accompanied by a much smaller increase in $\left[\mathrm{Ca}^{2+}\right]_{\mathrm{i}}$ than seen in the presence of extracellular calcium. Therefore, extracellular calcium indeed plays a role in the effect of CALP2 on radical production in 
alveolar macrophages, but certainly is not the only contributor. Since CALP2 increased $\left[\mathrm{Ca}^{2+}\right]_{\mathrm{i}}$ in the absence of extracellular calcium, CALP2 also stimulates calcium release from intracellular stores. The typical tracings of CALP2-induced radical production show that in calcium-free medium there is a large, temporary increase in radical production, whereas in the presence of extracellular calcium the radical production is more sustained. This could mean that first CALP2 releases calcium from intracellular stores, leading to the initial high radical production. Secondly, CALP2 opens storeoperated calcium channels, which results in a further increase in $\left[\mathrm{Ca}^{2+}\right]_{i}$, with the consequent more sustained production of radicals. ${ }^{18}$ The higher initial radical production after CALP2 stimulation in calcium-free medium is possibly due to a different kinetic profile of $\left[\mathrm{Ca}^{2+}\right]_{\mathrm{i}}$ under these conditions, leading to altered regulatory (feedback) mechanisms.

The combination of both intracellular calcium release and influx of extracellular calcium through store-operated channels results in the sustained radical production in alveolar macrophages. ${ }^{55}$ This hypothesis is confirmed by the fact that lanthanum, a selective inhibitor of store-operated calcium channels $\left(\mathrm{I}_{\mathrm{CRAC}}\right),{ }^{56}$ but not voltage-dependent calcium channel blockers like nifedipine or verapamil (data not shown), inhibited the action of CALP2. Furthermore, $\mathrm{I}_{\text {CRAC }}$ channels are present in macrophages and neutrophils but not in eosinophils ${ }^{57,58}$ Since CALP2 did not activate eosinophils, this further strengthens the hypothesis that CALP2, at least partly, acts via (store-operated) calcium channels. Furthermore, the $\mathrm{IP}_{3}$-receptor antagonist 2$\mathrm{APB}^{30}$ also partly inhibited the effect of CALP2. Hirota et $a l^{59}$ showed that binding of CaM to the $\mathrm{IP}_{3} \mathrm{R} 1$ receptor inhibits $\mathrm{IP}_{3} \mathrm{R}$ channel activity in a calcium-dependent manner. Furthermore, Zhang et $a l^{60}$ recently showed that inhibition of the inhibitory action of CaM is a key step in the activation of Drosophila Trp channels by IP3Rs. Taken together, these results suggest that CALP2 increases radical production by macrophages through inhibition of CaM, located in different parts of the cell.

As mentioned before, CALP2 increases NO production by airway epithelial cells, due to an increase of $\left[\mathrm{Ca}^{2+}\right]_{i}$ in epithelial cells and the consequent activation of the calcium/CaM-dependent constitutive nitric oxide synthase (cNOS). ${ }^{18}$ Since superoxide is also generated by different NOS isotypes, ${ }^{61}$ it is possible that CALP2 stimulates NOS in alveolar macrophages, leading to radical production. ${ }^{10}$ However, CALP2-induced increase in chemiluminescence was not inhibited by the NOS inhibitor LNAME (data not shown). We have shown that the CALP2-induced responses in macrophages can be inhibited by the NADPH-oxidase inhibitor DPI. ${ }^{62}$ Therefore, it seems likely that the NAPDH-oxidase, present in macrophages and neutrophils, ${ }^{63,64}$ is activated upon stimulation with CALP2. Indeed,
NADPH-oxidase activity is calcium-dependent ${ }^{64,65}$ and Jones et $a l^{64}$ suggested a role for CaM in the control of NADPH oxidase. Further, they found that not CaM alone, but the combination of calcium and $\mathrm{CaM}$ is needed for activation. This supports our hypothesis that CALP2 indirectly increases $\left[\mathrm{Ca}^{2+}\right]_{\mathrm{i}}$, which in turn activates NADPH oxidase.

Although CALP2 itself is an inhibitor of CaM, the CaM inhibitor W7 completely blocked the effects of CALP2. First, this can be explained by a direct effect of W7 on NADPH oxidase. In this case, W7 blocks the CALP2-induced radical production by inhibiting the effect of CALP2-released calcium on NADPH oxidase. Second, W7 can inhibit the CALP2-induced increase in $\left[\mathrm{Ca}^{2+}\right]_{\mathrm{i}}$ through blockage of the effects of CALP2 on store-operated calcium channels. Since CALP2 has an inverted hydropathic profile to CaM, it seems unlikely that W7 binds directly to CALP2 and therefore blocks the effect of CALP2. Furthermore, we earlier showed that CALP2 did not bind to CaM in the hydrophobic core, which is typical for W7, ${ }^{66}$ but rather interferes with the carboxyl-terminal calcium binding site of CaM. ${ }^{15}$ Moreover, it was recently shown that, depending on the protein bound to CaM, CaM undergoes marked different conformational changes, leading to changed calcium-binding. ${ }^{67}$ It is therefore assumed that W7 inhibits the action of CALP2 through a different inhibitory mechanism on CaM, leading to altered conformational changes.

A role for CaM in the activation of different cell types has been previously shown. The CaM antagonist W7 inhibited PAF-induced superoxide production by macrophages ${ }^{68}$ and calcium ionophore-triggered generation of superoxide by macrophages was dose-dependently inhibited by the CaM antagonist fluphenazine ${ }^{69}$ Interestingly, extracellular calcium had a predominant influence on the production of superoxide and nitric oxide in macrophages ${ }^{70}$ We show that, besides the influx of extracellular calcium, release from intracellular stores also plays a role in radical production. Although inhibition of radical production by CaM antagonist has been described earlier, ${ }^{64,69,71}$ we show that the combination of calcium/CaM is necessary for activation and, more importantly, calcium/CaM regulates activation to a different degree in certain cell types. Moreover, inhibition of radical production by CaM antagonists is dependent on the site of action on CaM, since the effect of CALP2 was blocked by W7.

We recently used CALP1 and CALP2 to investigate the role for $\mathrm{CaM}$ in the development of asthmatic features after ovalbumin challenge in an allergic asthma model in guinea-pigs. ${ }^{72}$ We found that specific modulation of CaM activity by CALP1 prevents the development of allergen-induced airway hyper-responsiveness, a key feature of asthma. Moreover, CALP1 inhibited PMA-induced radical production by BAL cells from ovalbumin-challenged animals. However, specific modulation of 
CaM activity by CALP2 had no influence on these asthmatic features. We postulated that the effects of CALP1 on airway hyper-responsiveness were due to the decreased radical production by alveolar macrophages in ovalbumin-sensitized and -challenged animals. In contrast, CALP2 has no effect on airway hyper-responsiveness, which is most likely due to an increased radical production by macrophages, leading to unaltered asthmatic features. Together, based on the current finding that CALP1 and CALP2 specifically act on alveolar macrophages, we postulate an important role for $\mathrm{CaM}$ in these cells for the development of asthmatic features. Alveolar macrophages may contribute to the development of asthma, since they produce numerous mediators including cytokines, growth factors, ROS and arachidonic acid derivatives. ${ }^{6}$ ROS increases airway smooth muscle contraction either directly ${ }^{73}$ or indirectly by influencing the reactivity of the airways to contractile and relaxing agonists. ${ }^{74}$ Moreover, they are involved in the development of airway hyper-responsiveness. ${ }^{50,75}$ Furthermore, ROS has several effects on other cells and structures involved in the pathology of asthma, such as blood vessels, nerves, epithelial- and inflammatory cells.

In conclusion, we found that the specific CaM modulator CALP2 is (1) a strong activator of alveolar macrophages, (2) a mild activator of alveolar neutrophils and (3) is unable to activate alveolar eosinophils. Since CALP2 is a selective CaM antagonist, the present study provides evidence that CaM regulates the production of reactive oxygen species by alveolar macrophages. Further, the calcium-binding site of $\mathrm{CaM}$ is likely to have stimulatory effects, whereas the hydrophobic core of CaM has inhibitory effects on radical production. Elucidation of the exact role of CaM in radical production may contribute to the development of new therapeutic strategies for the treatment of inflammatory diseases.

\section{Acknowledgement}

This work was supported by a research grant from Janssen Research Foundation, Beerse, Belgium (to FP Nijkamp) and in part by research Grants AI37670, NS29719, DK55647 (to JE Blalock) and HL68806 (to JE Blalock and FP Nijkamp) from the National Institutes of Health.

\section{References}

1 Busse WW, Lemanske Jr RF. Asthma. N Engl J Med 2001;344:350-362.

2 Saetta M. Airway inflammation in chronic obstructive pulmonary disease. Am J Respir Crit Care Med 1999;160:S17-S20.

3 Djukanovic R, Roche WR, Wilson JW, et al. Mucosal inflammation in asthma. Am Rev Respir Dis 1990;142:434-457.
4 Barnes PJ. Mechanisms in COPD: differences from asthma. Chest 2000;117:10S-14S.

5 Poulter LW, Janossy G, Power C, Sreenan S, Burke C. Immunological/physiological relationships in asthma: potential regulation by lung macrophages. Immunol Today 1994;15:258-261.

6 Shapiro SD. The macrophage in chronic obstructive pulmonary disease. Am J Respir Crit Care Med 1999; 160:S29-S32.

7 Babior BM. Oxygen-dependent microbial killing by phagocytes (first of two parts). N Engl J Med 1978;298:659-668.

8 Thannickal VJ, Fanburg BL. Reactive oxygen species in cell signaling. Am J Physiol Lung Cell Mol Physiol 2000;279:L1005-L1028.

9 Sadeghi-Hashjin G, Folkerts G, Henricks PA, et al. Peroxynitrite induces airway hyper-responsiveness in guinea pigs in vitro and in vivo. Am J Respir Crit Care Med 1996;153:1697-1701.

10 Saleh D, Ernst P, Lim S, Barnes PJ, Giaid A. Increased formation of the potent oxidant peroxynitrite in the airways of asthmatic patients is associated with induction of nitric oxide synthase: effect of inhaled glucocorticoid. FASEB J 1998;12:929-937.

11 Calhoun WJ, Reed HE, Moest DR, Stevens CA. Enhanced superoxide production by alveolar macrophages and air-space cells, airway inflammation, and alveolar macrophage density changes after segmental antigen bronchoprovocation in allergic subjects. Am Rev Respir Dis 1992;145:317-325.

12 Means AR, VanBerkum MF, Bagchi I, Lu KP, Rasmussen CD. Regulatory functions of calmodulin. In: Taylor CW (ed). Intracellular Messengers. Pergamon Press Ltd: Oxford 1991;pp265-285.

13 Persechini A, Moncrief ND, Kretsinger RH. The EFhand family of calcium-modulated proteins. Trends Neurosci 1989;12:462-467.

14 Sayeed MM. Exuberant $\mathrm{Ca}(2+)$ signaling in neutrophils: a cause for concern. News Physiol Sci 2001;15:130-136.

15 Villain M, Jackson PL, Manion MK, et al. De novo design of peptides targeted to the EF hands of calmodulin. J Biol Chem 2000;275:2676-2685.

16 Manion MK, Villain M, Pan ZG, et al. Cellular uptake and in situ binding of a peptide agonist for calmodulin. Biochem Biophys Res Commun 2000;277:462-469.

17 Houtman R, Ten Broeke R, Blalock JE, et al. Attenuation of very late antigen-5-mediated adhesion of bone marrow-derived mast cells to fibronectin by peptides with inverted hydropathy to EF-hands. J Immunol 2001;166:861-867.

18 Ten Broeke R, Folkerts G, Leusink-Muis T, et al. Calcium sensors as new therapeutic targets for airway hyperresponsiveness and asthma. FASEB J 2001;15:1831-1833.

19 Manion MK, Su Z, Villain M, et al. A new type of $\mathrm{Ca}(2+)$ channel blocker that targets $\mathrm{Ca}(2+)$ sensors and prevents $\mathrm{Ca}(2+)$-mediated apoptosis. FASEB J 2000;14:1297-1306.

20 Faulkner K, Fridovich I. Luminol and lucigenin as detectors for O2. Free Radic Biol Med 1993;15:447-451.

21 Aniansson H, Stendahl O, Dahlgren C. Comparison between luminol-and lucigenindependent chemiluminescence of polymorphonuclear leukocytes. Acta Pathol Microbiol Immunol Scand [C] 1984;92:357-361.

22 Minkenberg I, Ferber E. Lucigenin-dependent chemiluminescence as a new assay for NAD(P)H-oxidase 
activity in particulate fractions of human polymorphonuclear leukocytes. J Immunol Methods 1994;71:61-67.

23 Igarashi R, Hoshino J, Ochiai A, Morizawa Y, Mizushima Y. Lecithinized superoxide dismutase enhances its pharmacologic potency by increasing its cell membrane affinity. J Pharmacol Exp Ther 1994; 271:1672-1677.

24 Hancock JT, Jones OT. The inhibition by diphenyleneiodonium and its analogues of superoxide generation by macrophages. Biochem J 1987;242:103-107.

25 Cross AR, Jones OT. The effect of the inhibitor diphenylene iodonium on the superoxide-generating system of neutrophils. Specific labelling of a component polypeptide of the oxidase. Biochem J 1986; 237:111-116.

26 Osawa M, Kuwamoto S, Izumi Y, et al. Evidence for calmodulin inter-domain compaction in solution induced by W-7 binding. FEBS Lett 1999;442:173-177.

27 Schmidt J, Lindstaedt R, Szelenyi I. Characterization of platelet-activating factor induced superoxide anion generation by guinea-pig alveolar macrophages. J Lipid Mediat 1992;5:13-22.

28 Aussel C, Marhaba R, Pelassy C, Breittmayer JP. Submicromolar $\mathrm{La}^{3+}$ concentrations block the calcium release-activated channel, and impair CD69 and CD25 expression in CD3- or thapsigargin-activated Jurkat cells. Biochem J 1996;313:909-913.

29 Randriamampita C, Trautmann A. Biphasic increase in intracellular calcium induced by platelet-activating factor in macrophages. FEBS Lett 1989;249:199-206.

30 Maruyama T, Kanaji T, Nakade S, Kanno T, Mikoshiba K. 2APB, 2-aminoethoxydiphenyl borate, a membranepenetrable modulator of Ins(1,4,5)P3-induced $\mathrm{Ca}^{2+}$ release. J Biochem (Tokyo) 1997;122:498-505.

31 Verbrugh HA, Peters R, Peterson PK, Verhoef J. Phagocytosis and killing of staphylococci by human polymorphonuclear and mononuclear leucocytes. J Clin Pathol 1978;31:539-545.

32 Clark RA, Leidal KG, Pearson DW, Nauseef WM. NADPH oxidase of human neutrophils. Subcellular localization and characterization of an arachidonateactivatable superoxide-generating system. J Biol Chem 1987;262:4065-4074.

33 Henricks PA, Van Esch B, Engels F, Nijkamp FP. Effects of parainfluenza type 3 virus on guinea pig pulmonary alveolar macrophage functions in vitro. Inflammation 1993;17:663-675.

34 Alexis NE, Soukup J, Nierkens S, Becker S. Association between airway hyperreactivity and bronchial macrophage dysfunction in individuals with mild asthma. Am J Physiol Lung Cell Mol Physiol 2001; 280:L369-L375.

35 Chanez P, Bousquet J, Couret I, et al. Increased numbers of hypodense alveolar macrophages in patients with bronchial asthma. Am Rev Respir Dis 1991;144:923-930.

36 Fuller RW. The role of the alveolar macrophage in asthma. Respir Med 1989;83:177-178.

37 MacNee W. Oxidants/antioxidants and COPD. Chest 2000;117:303S-317S.

38 Sampson AP. The role of eosinophils and neutrophils in inflammation. Clin Exp Allergy 2000;1(Suppl 30):22-27.

39 Barnes PJ. Reactive oxygen species and airway inflammation. Free Radic Biol Med 1990;9:235-243.

40 Folkerts G, Kloek J, Muijsers RB, Nijkamp FP. Reactive nitrogen and oxygen species in airway inflammation. Eur J Pharmacol 2001;429:251-262.
41 Macnee W, Rahman I. Oxidants and antioxidants as therapeutic targets in chronic obstructive pulmonary disease. Am J Respir Crit Care Med 1999;160:S58-S65.

42 Droge W. Free radicals in the physiological control of cell function. . Physiol Rev 2002;82:47-95.

43 Lundqvist-Gustafsson $\mathrm{H}$, Bengtsson T. Activation of the granule pool of the NADPH oxidase accelerates apoptosis in human neutrophils. J Leukoc Biol 1999;65:196-204.

44 Grisham MB. A radical approach to treating inflammation. Trends Pharmacol Sci 2000;21:119-120.

45 Hallett $\mathrm{MB}$, Campbell AK. Is intracellular $\mathrm{Ca}^{2+}$ the trigger for oxygen radical production by polymorphonuclear leucocytes? Cell Calcium 1984;5:1-19.

46 Folkerts G, Nijkamp FP. Virus-induced airway hyperresponsiveness. Role of inflammatory cells and mediators. Am J Respir Crit Care Med 1995;151:1666-1673.

47 Folkerts G, Van Esch B, Janssen M, Nijkamp FP. Virusinduced airway hyperresponsiveness in guinea pigs in vivo: study of broncho-alveolar cell number and activity. Eur J Pharmacol 1992;228:219-227.

48 Nain M, Hinder F, Gong JH, Schmidt A, Bender A, Sprenger H, Gemsa D. Tumor necrosis factor-alpha production of influenza A virus-infected macrophages and potentiating effect of lipopolysaccharides. J Immunol 1990;145:1921-1928.

49 Beckman JS, Minor Jr RL, White CW, Repine JE, Rosen GM, Freeman BA. Superoxide dismutase and catalase conjugated to polyethylene glycol increases endothelial enzyme activity and oxidant resistance. J Biol Chem 1988;263:6884-6892.

50 Henricks PA, Nijkamp FP. Reactive oxygen species as mediators in asthma. Pulm Pharmacol Ther 2001;14: 409-420.

51 Ermak G, Davies KJ. Calcium and oxidative stress: from cell signaling to cell death. Mol Immunol 2002; 38:713-721.

52 Hoidal JR. Reactive oxygen species and cell signaling. Am J Respir Cell Mol Biol 2001;25:661-663.

53 de Leon $\mathrm{M}$, Wang $\mathrm{Y}$, Jones L, et al. Essential $\mathrm{Ca}(2+)$-binding motif for $\mathrm{Ca}(2+)$-sensitive inactivation of L-type Ca2+ channels. Science 1995;270: 1502-1506.

54 Levitan IB. It is calmodulin after all! Mediator of the calcium modulation of multiple ion channels. Neuron 1999;22:645-648.

55 Wheeler MD, Thurman RG. Production of superoxide and TNF-alpha from alveolar macrophages is blunted by glycine. Am J Physiol 1999;277:L952-L959.

56 Su Z, Csutora P, Hunton D, Shoemaker RL, Marchase $\mathrm{RB}$, Blalock JE. A store-operated nonselective cation channel in lymphocytes is activated directly by $\mathrm{Ca}(2+)$ influx factor and diacylglycerol. Am J Physiol Cell Physiol 2001;280:C1284-C1292.

57 Parekh AB, Penner R. Store depletion and calcium influx. Physiol Rev 1997;77:901-930.

58 Li SW, Westwick J, Poll CT. Receptor-operated Ca(2+) influx channels in leukocytes: a therapeutic target? Trends Pharmacol Sci 2002;23:63-70.

59 Hirota J, Michikawa T, Natsume T, Furuichi T, Mikoshiba K. Calmodulin inhibits inositol 1,4,5-trisphosphate-induced calcium release through the purified and reconstituted inositol 1,4,5- trisphosphate receptor type 1. FEBS Lett 1999;456:322-326.

60 Zhang Z, Tang J, Tikunova S, et al. Activation of Trp3 by inositol 1,4,5-trisphosphate receptors through displacement of inhibitory calmodulin from a common 
binding domain. Proc Natl Acad Sci USA 2001;98: 3168-3173.

61 Xia Y, Tsai AL, Berka V, Zweier JL. Superoxide generation from endothelial nitric-oxide synthase A. $\mathrm{Ca}^{2+} /$ calmodulin-dependent and tetrahydrobiopterin regulatory process. J Biol Chem 1998;273:25804-25808.

62 Robertson AK, Cross AR, Jones OT, Andrew PW. The use of diphenylene iodonium, an inhibitor of NADPH oxidase, to investigate the antimicrobial action of human monocyte derived macrophages. J Immunol Methods 1990;133:175-179.

63 Pinelli E, Cambon C, Tronchere H, Chap H, Teissie J, Pipy B. $\mathrm{Ca}(2+)$-dependent activation of phospholipases $\mathrm{C}$ and $\mathrm{D}$ from mouse peritoneal macrophages by a selective trigger of $\mathrm{Ca}^{2+}$ influx, gamma- hexachlorocyclohexane. Biochem Biophys Res Commun 1994; 199:699-705.

64 Jones HP, Ghai G, Petrone WF, McCord JM. Calmodulin-dependent stimulation of the NADPH oxidase of human neutrophils. Biochim Biophys Acta 1982; 714:152-156.

65 Jones HP, McCord JM. Calcium and calmodulin in neutrophil activation. Methods Enzymol 1984;105: 389-392.

66 Tanaka T, Ohmura T, Hidaka H. Calmodulin antagonists' binding sites on calmodulin. Pharmacology 1983;26:249-257.

67 Vandenberg JI, Lummis SC. Ion channels-a plethora of pharmaceutical targets. Trends Pharmacol Sci 2000; 21:409-410.

68 Hartung HP. Acetyl glyceryl ether phosphorylcholine (platelet-activating factor) mediates heightened metabolic activity in macrophages. Studies on PGE, TXB2 and O2-production, spreading, and the influence of calmodulin- inhibitor W-7. FEBS Lett 1983; 160:209-212.

69 Savitha G, Panchanathan S, Salimath BP. Capsaicin inhibits calmodulin-mediated oxidative burst in rat macrophages. Cell Signal 19990;2:577-585.

70 Hotchkiss RS, Bowling WM, Karl IE, Osborne DF, Flye MW. Calcium antagonists inhibit oxidative burst and nitrite formation in lipopolysaccharide-stimulated rat peritoneal macrophages. Shock 1997;8:170-178.

71 Beck-Speier I, Liese JG, Belohradsky BH, Godleski JJ. Sulfite stimulates NADPH oxidase of human neutrophils to produce active oxygen radicals via protein kinase $\mathrm{C}$ and $\mathrm{Ca}^{2+} /$ calmodulin pathways. Free Radic Biol Med 1993;14:661-668.

72 Ten Broeke R, Brandhorst MC, Leusink-Muis A, et al. $\mathrm{Ca}^{2+}$ sensors modulate asthmatic symptoms in an allergic model for asthma. Eur J Pharmacol 2003; 476:151-157.

73 Stewart RM, Weir EK, Montgomery MR, Niewoehner DE. Hydrogen peroxide contracts airway smooth muscle: a possible endogenous mechanism. Respir Physiol 2001;45:333-342.

74 de Boer J, Meurs H, Flendrig L, Koopal M, Zaagsma J. Role of nitric oxide and superoxide in allergeninduced airway hyperreactivity after the late asthmatic reaction in guinea-pigs. Br J Pharmacol 2001;133: 1235-1242.

75 Muijsers RB, van Ark I, Folkerts G, et al. Apocynin and $\mathrm{W}$ prevents airway hyperresponsiveness during allergic reactions in mice. Br J Pharmacol 2001;134:434-440. 